\title{
Counteracting Forces of Introgressive Hybridization and Interspecific Competition Shape the Morphological Traits of Cryptic Lberian Eptesicus Bats
}

\author{
Pedro Horta ( $\nabla$ pedro.horta@cibio.up.pt ) \\ University of Porto \\ Helena Raposeira \\ University of Porto \\ Adrián Baños \\ Pablo de Olavide University \\ Carlos Ibáñez \\ Estación Biológica de Doñana
}

Orly Razgour

University of Exeter

Hugo Rebelo

University of Porto

Javier Juste

Estación Biológica de Doñana

\section{Research Article}

Keywords: Adaptive introgression, Allopatry, Cryptic species, Eptesicus isabellinus, Eptesicus serotinus, Hybrids, Niche partitioning, Morphology, Sympatry

Posted Date: December 29th, 2021

DOI: https://doi.org/10.21203/rs.3.rs-1153883/v1

License: (c) (i) This work is licensed under a Creative Commons Attribution 4.0 International License. Read Full License 


\section{Abstract}

Cryptic species that coexist in sympatry are likely to simultaneously experience strong competition and hybridization. The first phenomenon would lead to character displacement, whereas the second can potentially promote morphological similarity through adaptive introgression. The main goal of this work was to investigate the effect of introgressive hybridization on the morphology of cryptic Iberian Eptesicus bats when facing counteracting evolutionary forces from interspecific competition. We found substantial overlap both in dentition and in wing morphology traits, though mainly in individuals in sympatry. The presence of hybrids contributes to a fifth of this overlap, with hybrids showing traits with intermediate morphometry. Thus, introgressive hybridization may contribute to species adaptation to trophic and ecological space responding directly to the macro-habitats characteristics of the sympatric zone and to local prey availability. On the other hand, fur shade tended to be browner and brighter in hybrids than parental species. Colour differences could result from partitioning of resources as an adaptation to environmental factors such as roost and microhabitats. We argue that a balance between adaptive introgression and niche partitioning shapes species interactions with the environment through affecting morphological traits under selection.

\section{1 | Introduction}

The evolutionary history of species under preliminary stages of macroevolution moves through complex forces, leading to incongruities in phylogenetic inferences and species classification [66]. Divergence is frequently discussed as involving mainly stages of allopatry $[10,72,78]$. However, historical environmental fluctuations [32] mediate iterations between periods of allopatry and sympatry [67, 70, 81]. When past allopatry was not sufficient to eliminate or significantly reduce niche overlap, closely-related species may coexist stably during secondary contacts under antagonistic evolutionary forces, imposed for example by hybridization and niche partitioning [76]. On one hand, under sympatry, genetic material can be transferred through introgressive hybridization with potential evolutionary convergence [79]. On the other hand, ecological interactions, such as competition, predation or parasitism may produce exclusion or promote divergence as a response [8].

When hybridization between lineages presents adaptive advantages in relation to the parental lines resulting in increased fitness, the genetic pools will face a process of adaptive introgression. This has been described as the main evolutionary response in natural hybridization $[7,24,29,43,48]$. Introgressed alleles potentially associated to well-adapted traits $[5,6,13,15,23,25,26]$ are introduced into the gene pool of the recipient species by backcrossing and fixed by natural selection $[20,79]$. Therefore, introgressed species can jump directly to new adaptive optimum, bypassing intermediate steps $[15,19]$. By allowing closely-related species to share particularly beneficial traits, adaptive introgression is sometimes understood as a homogenizing process promoting evolutionary convergence $[42,65]$.

Recent studies have shown important phenotypic expression of adaptive introgression in morphological traits of many taxa. Introgressed morphological traits were reported to promote dehydration/water-loss 
resistance to warmer or colder climates in plants, for example by increasing number or size of leaves, branches or roots under desert conditions [29]. Moreover, changes in body width, head shape or eye size were shown to promote higher fitness in some fishes [61], while larger heads with stronger bite and larger testes promoted better sexual performance in reptiles [90]. Introgression of morpho-physiological traits also promotes higher fitness in some rodents in environments with lower precipitation and temperatures [11]. Ancient events of adaptive introgression have even allowed humans to adapt to island environments by decreasing their size [55]. Colour change through adaptive introgression was reported in insects [19, $25]$, mammals $[36,50]$ and fishes $[49,53]$. Colour change is frequently associated with increasing mating performance $[74,90]$ better mimicry capacity $[58,91]$, higher success in escaping predators [92] and in exploring new habitats [53] and as responses, for example, to climate change [28, 36, 50, 92].

As an opposite evolutionary force, competition may lead species or lineages to avoid each other and to occupy a narrower and differentiated optima and set of conditions. If this effect is durable and prevalent enough, then it may lead to a species-specific divergent trait displacement due to a differential exploitation of resources $[51,69]$.

Competition has been reported to drive divergence in phenological traits, like changing floral shape of angiosperms in response to altitudinal gradients [40], and to promote functional and biomechanical differences in jaw closure of salamanders [4]. Moreover, competition has been shown to play a role in beak size divergence and larynx morphology in birds, both relevant traits for diet adaptations, and song characteristics, thus influencing sexual selection and species recognition [31]. Head morphology and size divergence were also described as being the result of competition in spadefoot toads, in response to omnivore or carnivore diet [68].

Despite the relevance of morphological traits for species adaptive capacity and individual fitness, the impact of hybridization on morphological traits when occurring in sympatry or parapatry remains largely unknown. Cryptic species are an extreme case among closely-related taxa for being morphologically identical but genetically distinct [35]. Due to their phylogenetic proximity and partial niche overlap, as well as morphological similarity and high potential for hybridization, they represent excellent case studies for the effect of antagonistic evolutionary processes on morphological trait displacement, particularly when associated with sympatric or parapatric distributions $[46,83]$.

Notably, in the Iberian Peninsula, over $20 \%$ of known bats species show cryptic diversity [33, 37]. Some of the cryptic species pairs exhibit high genetic divergence, such as Eptesicus serotinus [77] and $E$. isabellinus [82], which show over $16 \%$ divergence in the mtDNA Cytochrome b gene [33]. A comparative recent study supports a more pronounced and geographically structured intraspecific genetic variation within E. isabellinus [17]. This species has experienced a rapid post-glacial expansion earlier, heading northwards until occupying its current range. E. serotinus is thought to have expanded southwards from Central Europe, likely arriving later than $E$. isabellinus to the ecotone of central Iberia where both species meet [17]. Currently, E. serotinus is distributed along the Atlantic region of Iberia (colder and wetter) while E. isabellinus mainly occurs in the Mediterranean region (hotter and drier) [75]. Across their ranges, the 
two species geographically avoid each other, indicating that interspecific competition likely shaped their broad-scale distributions [63]. With a vast allopatric distribution, the species share a restricted contact zone, where they interbreed [17]. Although nuclear markers identified a male-mediated hybridization, there is no evidence of mitochondrial introgression, contrary to what is known for other Eptesicus [59]. Moreover, ongoing hybridization is asymmetric, occurring mainly from E. isabellinus to E. serotinus (28\% hybrids in E. serotinus colonies and $2.7 \%$ in E. isabellinus colonies) [17].

This study aims to understand the effect of this introgressive hybridization on morphological traits of the two cryptic Iberian Eptesicus bats in face of counteracting evolutionary forces from interspecific competition. We addressed three main objectives: 1) Test for morphological differences between cryptic Eptesicus species; 2) Determine the influence of sympatry and allopatry on patterns of morphological variation (wing, dentition and colour traits); 3) Assess the efficiency of classification statistics on species identification even in the presence of hybrids. Clarifying these objectives could elucidate how potential natural gene transfer through introgression can allow recipient bat species to incorporate into its genome alleles responsible for the presence of novel morphological traits.

\section{2| Methods}

\section{1 | Study area}

We searched for Eptesicus bat colonies between 1998 and 2014 along a North-South gradient across the Iberian Peninsula, including allopatric areas of only E. serotinus in the north, a central region of sympatric zone and allopatric areas of $E$. isabellinus in the south. Field sampling methods were described in previous publications $[17,75]$ as well as the location of all sampled colonies [17]. The methods were performed in accordance with relevant guidelines and regulations and approved by the Ethical committee at the EBD-CSIC (Estación Biologica de Doñana, Consejo Superior de Investigaciones Científicas) that granted protocol approval. The study was carried out in compliance with the ARRIVE guidelines

\section{2 | Sampling design}

Wing membrane biopsies ( $3 \mathrm{~mm}$ ) were collected according to Worthington-Wilmer and Barratt (1996) from all captured bats. The samples were kept in $96 \%$ ethanol at $-20^{\circ} \mathrm{C}$ until processed in the laboratory for molecular analysis to confirm species identification (see [17] for laboratory procedures).

Wing morphology variables were measured with a calliper and included the lengths of the forearm (FA), metacarpals of the III and V fingers and the first phalanges of the same fingers, as well as the length of the upper dental series (canine to third molar - CM3) and the rostral width measured at the canines' level (C1-C1) (Figure 1).

Coat colour was quantified by measuring the reflectance through a High Resolution Colorimeter (Spectrophotometer CM-2600d/2500d, Konica, Minolta). Two measurements were obtained for dorsal and ventral colours from each bat. Each measurement was the average of three light flashes' reflectance. 
Reflectance was measured at a wavelength band from 350 to $740 \mathrm{~nm}$ and was decomposed according to the colour space defined by CIELAB colour space, which included three parameters, $L^{\star}, a^{\star}$ and $b^{\star}$. $L^{*}$ represents perceptual lightness, and $a^{\star}$ and $b^{\star}$ a four colours' scale, from red to green and blue to yellow, respectively (Figure S1) [34].

To study the effect of interspecific responses of E. serotinus and $E$. isabellinus and their hybrids, bats were clustered into five experimental groups: allopatric $E$. isabellinus, sympatric $E$. isabellinus, hybrids (individuals classified as hybrids by Centeno-Cuadros et al. (2019) based on genetic data, using a conservative criteria), sympatric E. serotinus and allopatric $E$. serotinus. We assumed that both species were geographically isolated from each other and the respective hybrids within the allopatric groups. On the contrary, in the sympatric groups, each species co-existed with the other species and their hybrids. The geographic classifications of each experimental group were based on previous studies $[17,33,75]$.

\section{3 | Statistical analyses}

The effect of geographic origin and hybrids presence on bat morphometry

We used General Linear Models to assess whether geographic relationships significantly affected the morphometry and/or the colour of the studied bats. We performed a non-parametric MANOVA [45] on the morphological variables because homogeneity of variance could not be assumed according to the Box's $M$ tests (Morphometry: Box's $M=133.73 ; F_{(84,16828.68)}=1.393 ; n s ;$ Colour: Box's $M=215.69 ; F_{(63}$, $1824.12)=2.480$; ns) even after trying several data transformations ( $\log _{10}, \ln$, arcsen, etc.). We performed a Kruskal-Wallis test to identify which morphometric traits and colour variables were significantly different, followed by multiple comparisons by the post-hoc Fisher's LSD test to check for differences between groups [45].

\section{Summarizing and comparing morphological variables}

The original morphometric space of the wing and dentition variables was summarized into its main components by a principal component analysis (PCA) with the symmetrical normalization method [45]. The eigenvalue rule greater than 1 was used as criterion for components' retention alongside the screeplot. We analysed the internal consistency of each component through Cronbach's alpha [45].

After the validation of both assumptions for multivariate normal distribution and homogeneity of variance-covariance $\left(M=13.98 ; F_{(12,7934.55)}=1.104, p=0.352\right)$, we performed a MANOVA over the PCA's axes to evaluate the relationship of the five experimental groups with morphometric traits. When the MANOVA detected significant effects, we performed an ANOVA for each component (PC1 and PC2), followed by multiple comparison through Tukey's HSD post-hoc test. Again, according to the Box's M tests, even after transformation, the homogeneity of covariance could not be assumed (Box's $M=30.41$; $\left.F_{(12,2323.67)}=2.250 ; n s\right)$ for retained colour's PCA. In order to assess whether geographic origin affected colour variables, we performed a non-parametric MANOVA [45], followed by the tests described above 
[45]. We carried out all analyses with $a=0.05$ in SPSS Statistics software (v. 22; SPSS Inc, Chicago, IL), producing all visualizations through "ggplot2" R package [87].

\section{Classification statistics with and without hybrids' presence}

We used two classification algorithms to classify both species in sympatry according to the morphological variables: discriminant function analysis (DFA - quadratic with cross-validation) and the support vector machines (SVM - with a machine learning approach).

The morphometric matrices fulfils the assumptions of normal distribution and homogeneity of variance so we proceeded with parametric analyses (Morphometry with hybrids: Box's $M=38.33 ; F_{(28}$,

$32463.13)=1.267 ; p=0.157$; Morphometry without hybrids: Box's $\left.M=11.10 ; F_{(10,5819.66)}=0.996 ; p=0.444\right)$.

The data were firstly included in two stepwise discriminant analyses with the method of Wilks' $\wedge$ used to identify which of the morphological and colour variables under study can better discriminate both parental species with and without the presence of hybrids. Again, homogeneity of the variancecovariance matrices could not be assumed for the colour variables (Colour with hybrids: Box's $M=37.65$, $F_{(10,11071.13)}=3.474$, ns; Colour without hybrids: Box's $M=38.06, F_{(10,4588.83)}=3.414$, ns). Still, we proceeded with analysis because the discriminant analysis is robust to violation of assumptions when (i) the size of the smallest group (sympatric E. serotinus) is greater than the number of variables in the study and (ii) the means of the groups are not proportional to their variances [45]. Finally, we used Classification Statistics to obtain the classification functions and to assign species identification according to morphometric traits and/or colour variables. All DFA analyses were carried out with $a=0.05$.

In addition, a support-vector machine (SVM) algorithm was performed using the principal components extracted from each PCA (morphometry and colour), through "tidyverse" (performing data manipulation) [87], "kernlab" [39] and "e1071" R packages [52] (performing calculations and producing visualizations). The kernel functions of the support vector machines used a radial basis function with a gamma parameter ranging from $0.1,1,10,100$ and 1000 . For each value of gamma, the SVM was reinitialised 20times to increase the chance of obtaining an optimal classifier [71, 73]. For Classification Statistics the algorithm of the SVM was trained for every target case in the dataset (each species) [71]. All classifiers were then combined and categorised for each morphological trait as either belonging to a specific class, or not. Each bat was considered as classified correctly only if a single support vector machine classified it and if validated by molecular identification.

Quantification of the impact of the hybrids on the external morphological traits overlap between species

We repeated the entire statistical procedure after extracting from the dataset all individuals classified as hybrids in Centeno-Cuadros et al. (2019). We compared the classification performance of both algorithms in the sympatric population with hybrids versus the same population after excluding them. This approach made it possible to calculate the contribution of hybrids to the overlap of morphological traits with their cryptic parental species. 


\section{3 | Results}

\subsection{Testing for morphological differences between cryptic Eptesicus species}

Our results showed significant differences of both morphometric and colour variables along the experimental groups. Morphometric differences occurred for the variables FA, D3 MC, D5 MC, D5 F1, C1$\mathrm{C} 1$ and CM3 but not for the variable D3 F1 (Table 1). For coat colour, we found significant differences between the groups in the variables $L^{*}$ dorsal, $a^{*}$ dorsal, $b^{*}$ dorsal, $a^{*}$ ventral and $b^{*}$ ventral, but not for the variable $L^{*}$ ventral (Figure 2). The information between both morphometric and colour variables was summarized in two main orthogonal components, explaining respectively $59.8 \%$ and $83.4 \%$ of the total variance of the original morphometric and colour variables (Table S2). The first morphometric component was associated with bats' "Size", whereby generally, the weight of all variables was very high and positive. The second morphometric component essentially summarized the wing "Shape", namely the metacarpals and first phalanges proportion. Additionally, the inversely proportional relationship between the length of the first phalanges and the dentition variables, mainly $\mathrm{CM} 3$, had a very high and negative score in this second component (Table S2). Despite an evident overlap, the two-dimensional PCA map showed that $E$. serotinus is generally larger in both wing and dentition, particularly in the allopatric zone with respect to $E$. isabellinus. In sympatry there was a greater overlap between both species despite maintaining the same pattern (Figure 3). 
Table 1

Descriptive statistics of the morphometric traits of Eptesicus serotinus, E. isabellinus and their hybrids.

Wing

Dentition

\begin{tabular}{|c|c|c|c|c|c|c|c|}
\hline & FA & D3 MC & D3 F1 & D5 MC & D5 F1 & $\mathrm{C} 1-\mathrm{C} 1$ & $\mathrm{CM} 3$ \\
\hline E. isabellinus & 51.6 & 47.1 & 17.8 & 44.1 & 10.9 & 6.7 & 7.2 \\
\hline $\begin{array}{l}\text { (Eisa allo; } n=31 \\
\text { individuals) }\end{array}$ & $\begin{array}{l}49.9- \\
55.7\end{array}$ & $\begin{array}{l}44.0- \\
52.0\end{array}$ & $\begin{array}{l}12.2- \\
19.8\end{array}$ & $\begin{array}{l}41.3- \\
48.0\end{array}$ & $\begin{array}{l}10.0- \\
12.0\end{array}$ & $\begin{array}{l}6.3- \\
7.2\end{array}$ & $\begin{array}{l}6.8- \\
7.7\end{array}$ \\
\hline $\begin{array}{l}\text { E. isabellinus } \\
\text { sympatric }\end{array}$ & 51.6 & 46.1 & 18.0 & 43.0 & 11.3 & 6.9 & 7.2 \\
\hline $\begin{array}{l}\text { (Eisa sym; } n=33 \\
\text { individuals) }\end{array}$ & $\begin{array}{l}48.6- \\
54.3\end{array}$ & $\begin{array}{l}42.6- \\
48.6\end{array}$ & $\begin{array}{l}16.5- \\
20.5\end{array}$ & $\begin{array}{l}40.1- \\
48.5\end{array}$ & $\begin{array}{l}10.2- \\
12.6\end{array}$ & $\begin{array}{l}6.3- \\
7.4\end{array}$ & $\begin{array}{l}6.5- \\
8.4\end{array}$ \\
\hline Hybrids & 52.6 & 46.8 & 18.8 & 43.4 & 12.0 & 6.7 & 7.4 \\
\hline ( $\mathrm{n}=8$ individuals) & $\begin{array}{l}49.7- \\
53.7\end{array}$ & $\begin{array}{l}42.7- \\
47.7\end{array}$ & $\begin{array}{l}16.8- \\
19.1\end{array}$ & $\begin{array}{l}39.9- \\
45.9\end{array}$ & $\begin{array}{l}11.0- \\
13.3\end{array}$ & $\begin{array}{l}6.5- \\
6.9\end{array}$ & $\begin{array}{l}7.1- \\
7.5\end{array}$ \\
\hline $\begin{array}{l}\text { E. serotinus } \\
\text { sympatric }\end{array}$ & 52.8 & 47.5 & 17.8 & 44.5 & 11.7 & 6.9 & 7.6 \\
\hline $\begin{array}{l}\text { (Eser sym; } n=19 \\
\text { individuals) }\end{array}$ & $\begin{array}{l}49.7- \\
55.2\end{array}$ & $\begin{array}{l}44.7- \\
49.7\end{array}$ & $\begin{array}{l}16.8- \\
20.4\end{array}$ & $\begin{array}{l}40.5- \\
47.2\end{array}$ & $\begin{array}{l}9.9- \\
13.1\end{array}$ & $\begin{array}{l}6.6- \\
7.5\end{array}$ & $\begin{array}{l}7.3- \\
8.5\end{array}$ \\
\hline $\begin{array}{l}\text { E. serotinus } \\
\text { allopatric }\end{array}$ & 52.6 & 49.0 & 18.0 & 46.5 & 11.3 & 6.9 & 7.7 \\
\hline $\begin{array}{l}\text { (Eser allo; } \mathrm{n}=35 \\
\text { individuals) }\end{array}$ & $\begin{array}{l}48.8- \\
56.1\end{array}$ & $\begin{array}{l}41.4- \\
51.6\end{array}$ & $\begin{array}{l}13.2- \\
19.5\end{array}$ & $\begin{array}{l}41.6- \\
49.6\end{array}$ & $\begin{array}{l}10.0- \\
12.5\end{array}$ & $\begin{array}{l}6.6- \\
7.5\end{array}$ & $\begin{array}{l}7.4- \\
8.7\end{array}$ \\
\hline$X^{2}{ }_{K S}(4)$ & 13.302 & 38.271 & 1.698 & 25.234 & 12.244 & 15.300 & 64.410 \\
\hline$p$-value & 0.010 & $<0.001$ & $n s$ & $<0.001$ & 0.016 & 0.004 & $<0.001$ \\
\hline
\end{tabular}

E. isabellinus both in allopatry and sympatry showed a greater proportion between first phalanges and both metacarpals (e.g. smaller ratio of length of both metacarpals to first phalange), revealing an inversely proportional relationship between the length of the first phalanges and both dentition variables (larger phalanges and smaller C1-C1 and mainly CM3) (Figure 3). In contrast, E. serotinus revealed, in both sympatry and allopatry, to have substantially smaller first phalanges relative to metacarpals, as well as to both dentition variables (mainly CM3) (Figure 3).

The first colour component of the PCA was associated with a range of colours from grey to brown, named as "a*b* Grey-Brown scale", while the second component essentially summarized the "L*Brightness" (Table S2). Despite an evident overlap, it was possible to characterize allopatric $E$. serotinus as being darker and greyer by showing a combination of higher black, green and yellow 
components in both dorsal and ventral colourations (Figure 4). All the remaining groups varied mainly along the brown pallet by having higher values for red and blue. Sympatric E. serotinus was in the other extreme of that Grey-Brown colour pallet, being the brownest group (Table S4). Likewise, sympatric $E$. serotinus shared the darkest position with allopatric E. serotinus, into brightness scale ("L* brightness"). Allopatric $E$. isabellinus was the brightest group. In sympatry, once again, $E$. isabellinus showed brightest colour patterns. The ventral colour was always brighter than the dorsal one in all experimental groups due to its higher $L *$ values, showing even more subtle colour differences between groups (Figure 2).

\section{Sympatry vs Allopatry - influence on morphology}

There were no significant differences in the bats' size and shape between allopatric and sympatric groups within each species (except in metacarpals). However, all morphological variables differed significantly between allopatric groups. Regarding morphometric variables (D5 MC, D5 F1 and C1C1), especially for bats' "shape", these significant differences disappear in sympatry (a detailed description of the morphometric comparisons is available in Supplemental material).

Regarding the colour variables, all experimental groups differed significantly from allopatric $E$. serotinus in the $a * b *$ Grey-Brown scale, which were the only individuals in the grey range of the colour pallet. In terms of brightness, allopatric $E$. serotinus was only not significantly different from individuals of the same species when in sympatry (bats were equally dark, though in sympatry they tended to be significantly browner). In sympatry, both species also differed significantly, however, contrary to the morphometric variables, this difference was slightly greater than that found between species in allopatry.

\section{Hybrids vs Parental species - impact of hybridization on morphology}

Hybrids did not differ significantly from the other groups of allopatry/sympatry in wing size (except for metacarpals), showing intermediate wing morphometric values relative to both parental species. Hybrids differed significantly in the dentition between the two species, even in comparison with both sympatric groups with which they coexist (e.g. CM3). Nonetheless, hybrids showed consistently intermediate phenotypes in both dentition and wing size, as well as wing shape (a detailed description of the morphometric comparisons between hybrids and parental species is available in the Supplemental material).

Hybrids showed the brightest pelage colour (both in their dorsal and ventral coat), although not significantly different from E. isabellinus in both groups (sympatry and allopatry) (Figure 3; Table S5). On the other hand, hybrids were significantly browner than allopatric E. serotinus and they were also the brownest group together with sympatric E. serotinus (Table S5).

\section{2 | Species discrimination through classification statistics}

Stepwise DFA with and without hybrids 
The morphometric stepwise DFA generated one discriminant function mainly defined by D3_MC and CM3 $\left(\Lambda=0.579, \chi^{2}{ }_{(7)}=53.773, p<0.001\right)$. The percentage of individuals classified correctly in the presence of hybrids was $81.7 \%$. After hybrids removing, discriminant analysis generated also one discriminant function, with FA, D3_MC, D5_MC (marginally significant $[\mathrm{F}=3.450, p=0.069]$ ) and $\mathrm{CM} 3$ as statistically significant variables $\left(\Lambda=0.632, \chi^{2}{ }_{(4)}=21.073, p<0.001\right)$. The results of Classification Statistics showed that the total percentage of individuals classified correctly increased to $84.0 \%$ after hybrids removing.

The colour stepwise DFA generated also only one discriminant function, with $L^{*}$ _dorsal, a*_dorsal, $b^{\star}$ _dorsal and $L^{\star}$ _ventral as statistically significant variables $\left(\Lambda=0.842, \chi^{2}{ }_{(4)}=10.115, p=0.039\right)$. The percentage of individuals classified correctly in the presence of hybrids was $71.4 \%$. After removing the hybrids, the colour discriminant analysis generated also one discriminant function, once again with $L^{*}$ _dorsal, a*_dorsal, b*_dorsal and L*_ventral as statistically significant $\left(\Lambda=0.762, \chi^{2}{ }_{(4)}=14.114\right.$, $p=0.007$ ). The results of Classification Statistics showed that the total percentage of individuals classified correctly increased to $78.6 \%$ after hybrids removing.

\section{Support Vector Machine with and without hybrids}

SVM generated one discriminant function based on morphometric PC1 and PC2 as predictors' variables that summarized all morphometric traits. After simulations, the results of Classification Statistics showed that the percentage of individuals classified correctly in the presence of hybrids was $75.0 \%$. Without hybrids, SVM generated also one discriminant function. The percentage of individuals classified correctly increased to $76.9 \%$ after removing hybrids.

Based on colour PC1 and PC2 as predictors' variables, SVM generated also one discriminant function. After simulations, the results of Classification Statistics showed that the percentage of individuals classified correctly in the presence of hybrids was $68.3 \%$. After hybrids removing, the colour SVM also generated one discriminant function. The results of Classification Statistics showed that the total percentage of individuals classified correctly increased to $76.8 \%$ after removing hybrids (detail description is available in Supplemental Material).

Finally, both species showed a statistically significant differential behaviour in relation to the correct classification rate for both classification methods tested $\left(\chi^{2}{ }_{k W}(1)=10.678, p=0.01, \mathrm{~N}=16\right)$ and $E$. isabellinus individuals were significantly classified correctly than the individuals of $E$. serotinus ( $\mathrm{F}=15.976 ; p=0.001)$ (Table 2). 
Table 2

Correct species classification rates, species overlap and hybrids contribution to species overlap obtained by two different methods of classification statistics (DFA and SVM) based on morphometric and colour traits of E. isabellinus and E. serotinus in sympatry.

\begin{tabular}{|lll|}
\hline & DFA & SVM \\
\cline { 2 - 3 } & Morphometry \\
\hline E. isabellinus correct classification rate & $84.5 \%$ & $78.9 \%$ \\
\hline E. serotinus correct classification rate & $78.3 \%$ & $72.3 \%$ \\
\hline E. isabellinus correct classification rate without hybrids presence & $96.0 \%$ & $83.9 \%$ \\
\hline E. serotinus correct classification rate without hybrids presence & $66.7 \%$ & $66.7 \%$ \\
\hline Global correct classification rate & $\mathbf{8 1 . 7 \%}$ & $75.0 \%$ \\
\hline Global correct classification rate without hybrids presence & $84.0 \%$ & $76.9 \%$ \\
\hline Overlap in sympatry & $18.3 \%$ & $25.0 \%$ \\
\hline Hybrids contribution to species overlap & $13.6 \%$ & $7.6 \%$ \\
\hline & Colour & \\
\hline E. isabellinus correct classification rate & $92.3 \%$ & $92.3 \%$ \\
\hline E. serotinus correct classification rate & $37.5 \%$ & $29.2 \%$ \\
\hline E. isabellinus correct classification rate without hybrids presence & $92.3 \%$ & $77.1 \%$ \\
\hline E. serotinus correct classification rate without hybrids presence & $47.1 \%$ & $75.0 \%$ \\
\hline Global correct classification rate & $71.4 \%$ & $68.3 \%$ \\
\hline Global correct classification without hybrids presence & $78.6 \%$ & $76.8 \%$ \\
\hline Overlap in sympatry & $28.6 \%$ & $\mathbf{3 1 . 7} \%$ \\
\hline Hybrids contribution to species overlap & $25.2 \%$ & $\mathbf{2 6 . 8} \%$ \\
\hline
\end{tabular}

General impact of introgressive hybridization on classification success

Based on the two tested algorithms and the two sets of traits (morphometry and colour), the overlap between the two parental species was around $25.9 \pm 5.76 \%$. The contribution of hybrids to overlap among parental species was significantly higher for colour $(26.0 \pm 1.13 \%)$ than morphometry $(10.6 \pm 4.24 \%)$ $(\mathrm{F}=24.602 ; p=0.038)$. Overall, hybrids contributed on average $18.3 \pm 9.25 \%$ to traits overlapping between their parental species (Table 2).

\section{4 | Discussion}


Differences in morphology have been commonly used to differentiate taxa undergoing preliminary steps of macroevolution. However, as predicted by the particular challenges posed by the similarity of cryptic species, overlap in all morphological variables was the most evident pattern. Yet, for the two species of Iberian Eptesicus the differences in size and shape were strikingly larger when comparing allopatric populations than when comparing populations in sympatry. Still, the high overlap in all morphological traits meant that no single variable could be used as a diagnostic characteristic to distinguish the two species. Even so, the analyses of the external morphological traits (wing and dentition) confirmed that $E$. serotinus is slightly, but significantly, larger and darker than $E$. isabellinus. Although allopatric E. serotinus bats showed a greyer coat, the remaining four groups were distributed along the brown pallet, with sympatric groups showing the brownest coat. Molecularly confirmed hybrids showed intermediate morphometric values between both parental species in terms of size and shape, particularly when compared to allopatric populations. Hybrids were significantly browner than allopatric E. serotinus, showing the brightest coats of all, significantly brighter than both allopatric and sympatric $E$. isabellinus. Thus, alongside a probable process of adaptation to the local environmental conditions in the sympatric zone, bidirectional adaptive introgression (even if asymmetrical) can lead to convergence in size and shape, increasing morphological overlap among parental species [32]. Hybrids, distributed along a sympatric zone, show intermediate values in morphometric traits (both in size and shape), while differences between both parental species in morphometry decreased significantly in sympatry. Therefore, it is probable that hybridization and adaptive introgression affect the morphology of the parental species through backcrossing $[11,29,61,90]$.

External traits are priority targets for natural selection as they directly impact the fitness of individuals and the ecological niche in which they occur [64]. According to Grant and Grant (2016), it is possible to make genetic inferences grounded in two morphological aspects, size and shape, due to the narrow connection between introgressed alleles and species morphology. This fact is based on high frequency of heritable variation and polygenic origin of external traits [30]. This relationship is supported by evidence from genes that were identified as regulating the development of vertebrate' size and shape [2, 3, 44]. There is considerable amount of evidence that supports the influence of adaptive introgression on morphometry impacting both size and shape $[11,61,85,90]$. Adaptive introgression consequences seem plastic enough to be able to promote divergent adaptations in response to the particularities of environmental conditions [29]. For example, adaptive introgression events promoted size reduction in ancient humans, allowing them to adapt to insular environments [55], while on the other hand they enabled carnivores to obtain larger prey by increasing their body size [85].

Adaptive introgression of bat morphological traits should respond to the circumstances in which they cooccur within the sympatric zone. Adaptive introgression in Eptesicus dentition and wing morphology, for example, could impact their trophic space, being connected to their diet, as well as their ecological niches, responding directly to the macro-habitat characteristics of the sympatric zone and to local prey availability. With increasing dentition size, E. isabellinus is more able to capture larger prey, while the smaller dentition of E. serotinus makes it more efficient in capturing smaller prey [80]. On the other hand, increased wing size and shape changes (namely decreasing the proportion between first phalanges and 
metacarpals) may have enabled $E$. isabellinus to become more efficient in exploring more open habitats [38] and disperse over longer distances [56]. In contrast, decreased wing length and shape changes (namely increasing the proportion between first phalanges and metacarpals) may have rendered $E$. serotinus more prone to explore close habitats than those used in allopatry [38].

Mammals are not frequently colourful being mostly colour-blind to the red-green spectrum because they tend to be crepuscular or nocturnal [12]. Bats are an extreme example of it. Under low-light conditions, dichromatic vision seems to be advantageous over colour vision because the reduced number of coloursensitive cones in the retina means they focus on more light-sensitive rods, thus improving their visual acuity [57]. Similar to other nocturnal mammals, bats are commonly shades of black, grey or brown, with only small colour differences between species [88]. Thus, the differences found in bat colours are substantially smaller than morphometric ones. Still, contrary to the patterns found in morphometry, colour characteristics of hybrids are in the extreme of the brown colour palette. In parallel, they are also consistently the brightest ones. Still, the differences in colour parameters of both parental species seem slightly greater in sympatry.

Colour patterns have been linked to communication and physiological processes, such as thermoregulation [16]. However, most bats use vocal and olfactory cues rather than visual signals to perceive the environment and for social interactions [18]. On the other hand, brighter colours cannot affect mating recognition without the development of tri- or tetra-chromatic vision [16]. Bat colouration is most probably the result of adaptation to a nocturnal niche, likely associated with concealment from predators [16]. So, bats colouration should reflect environmental pressures, for example, from the roosts that they occupy. Different colour patterns can be expected in species occupying different types of roosts because roost conditions differ in their visual environment (e.g. luminance and colour spectrum), as well as in their level of exposure to twilight or diurnal predators [16].

The two Iberian Eptesicus species do not share roosts, despite their colonial behaviour with nursery colonies comprising up to 300 animals [22], and their tendency to share roosts with other species [47]. This suggests that these two bats may compete actively for the best spots when in sympatry. E. serotinus colonies are mainly associated with buildings in Central Europe [21], while in the Mediterranean region, they also roost in crevices of cliffs and at the entrance of caves [22]. E. isabellinus, instead, seems to prefer crevices (cliffs or bridges) and tree hollows in date palms in North Africa [41].

Resource partitioning and geographic avoidance have been described for several pairs of cryptic bat species across Europe $[60,62,63]$. Cryptic species can exploit different microhabitats and roosts to avoid competition when sharing the same sympatric area [62], and this may be the case for the Iberian Eptesicus in sympatry. Therefore, roost-mediated coevolution could be one plausible hypothesis to explain the different colour patterns in the bats. The light environment of nocturnal niches can be dominated by yellow-green wavelengths, for example in more closed foraging spots, which coincides with the spectral sensitivity of bats [27]. Therefore, the natural pressure of nocturnal light conditions occurring over the various microhabitats that are explored by each species in sympatry may have interacted with 
diurnal light conditions in roosts to favour the pelage colour differences in Eptesicus. Thus, any possible differences promoted by the interactions between the two cryptic bats in sympatry through potential competition for roosts and microhabitats will not only have consequences for their colour and their discrimination, but fundamentally for their interactions with predators and the environment [86].

The extent of morphological overlap between the two cryptic bats was around $26 \%$. The presence of hybrids contributes substantially to a fifth of the total traits overlap. Even so, classification statistics showed high differentiation rate between the two parental species in sympatry, particularly for $E$. isabellinus, with higher correct identification rates for morphometric traits, which were more distinct than colour.

Discriminant functions showed D3_MC and CM3 are the main variables discriminating between the species. However, only CM3 showed limited overlap between them with values below $7.3 \mathrm{~cm}$ found only in $E$. isabellinus, whereas values above $8.4 \mathrm{~cm}$ only in $E$. serotinus. Therefore $\mathrm{CM} 3$ is the only measure that can be used to confidently distinguish between the two species.

Morphological diversity is a critical facet of evolution and adaptation [9]. However, morphology is also extremely important for field identification, particularly for endangered species. Accurate field identification is particularly important for Eptesicus species because they are hosts of different lineages of the European bat Lyssavirus type 1 (EBLV-1), the most common rabies related virus found in European bats [54, 84]. Moreover, using morphological traits for cryptic species identification in sympatry, instead

of molecular approaches that are frequently used for in-situ identification, could be particularly useful due to the reduced associated costs.

\section{Caveats and limitations}

We classified individuals as hybrids following Centeno-Cuadros et al. (2019) and applying the conservative criteria proposed by Burgarella et al. (2009) to the microsatellite genotypes to guarantee there were no misclassifications. On the other hand, this approach does not allow us to exclude the possibility of the presence of other possible hybrids in the other sympatric groups. In addition, the lab methodology used to detect hybrids does not detect the presence of second generation and later hybrids, as well as backcrosses. These potential overlooked hybrids may be falsely inflating the overlap between morphological characteristics of the two sibling bat species. Despite this, we still obtained high values of correct identifications in the classification statistics, which indicates that the proportion of undetected hybrids was low.

\section{5 | Conclusions}

We demonstrated that cryptic Iberian Eptesicus species can coexist during secondary contacts under antagonistic evolutionary forces, imposed simultaneously by introgressive hybridization and potential niche-partitioning. This balance may be driven by the partitioning of resources along two niche axes, microhabitats and roosts. The situation may be different in other niche axes, such as trophic resources, 
prey characteristics and macro-habitats, which are under adaptive pressure from local conditions. Divergence due to niche differentiation and adaptive introgression should impact on different aspects of morphology [1]. The latter seems to have a greater effect on the divergence of bat pelage colour. Instead, adaptive introgression seems to act as a homogenising force over morphometric traits, such as wing and dentition shape and size. Finally, we argue that a balance between adaptive introgression and interspecific competition, beyond mediating species divergence, shapes their interactions with the environment by impacting morphological traits under selection.

\section{References}

1. Abrams, P.A. (1986). Character displacement and niche shift analyzed using consumer-resource models of competition. Theoretical population biology 29, 107-160.

2. Abzhanov, A., Kuo, W.P., Hartmann, C., Grant, B.R., Grant, P.R., and Tabin, C.J. (2006). The calmodulin pathway and evolution of elongated beak morphology in Darwin's finches. Nature 442, 563-567.

3. Abzhanov, A., Protas, M., Grant, B.R., Grant, P.R., and Tabin, C.J. (2004). Bmp4 and morphological variation of beaks in Darwin's finches. Science (New York, NY) 305, 1462-1465.

4. Adams, D.C., and Rohlf, F.J. (2000). Ecological character displacement in <em>Plethodon</em>: Biomechanical differences found from a geometric morphometric study. Proceedings of the National Academy of Sciences 97, 4106-4111.

5. Aleksic, J.M., Skondric, S., and Lakusic, D. (2018). Comparative phylogeography of capitulate Campanula species from the Balkans, with description of a new species, C-daucoides. Plant Systematics and Evolution 304, 549-575.

6. Alexander, A.M., Su, Y.C., Oliveros, C.H., Olson, K.V., Travers, S.L., and Brown, R.M. (2017). Genomic data reveals potential for hybridization, introgression, and incomplete lineage sorting to confound phylogenetic relationships in an adaptive radiation of narrow-mouth frogs. Evolution; international journal of organic evolution 71, 475-488.

7. Anderson, E., and Hubricht, L. (1938). Hybridization in Tradescantia. III. The evidence for introgressive hybridization. American Journal of Botany 25, 396-402.

8. Anderson, R.P., Peterson, A.T., and Gómez-Laverde, M. (2002). Using niche-based GIS modeling to test geographic predictions of competitive exclusion and competitive release in South American pocket mice. Oikos 98, 3-16.

9. Anderson, T.M., vonHoldt, B.M., Candille, S.I., Musiani, M., Greco, C., Stahler, D.R., Smith, D.W., Padhukasahasram, B., Randi, E., Leonard, J.A., et al. (2009). Molecular and evolutionary history of melanism in North American gray wolves. Science (New York, NY) 323, 1339-1343.

10. Baiz, M.D., Tucker, P.K., and Cortés-Ortiz, L. (2019). Multiple forms of selection shape reproductive isolation in a primate hybrid zone. Molecular ecology 28, 1056-1069.

11. Boratyński, Z., Alves, P.C., Berto, S., Koskela, E., Mappes, T., and Melo-Ferreira, J. (2011). Introgression of mitochondrial DNA among Myodes voles: consequences for energetics? BMC Evolutionary 
Biology 11, 355.

12. Bradley, B.J., and Mundy, N.I. (2008). The primate palette: The evolution of primate coloration. Evolutionary Anthropology Issues News and Reviews 17, 97-111.

13. Brower, A.V.Z. (2013). Introgression of wing pattern alleles and speciation via homoploid hybridization in Heliconius butterflies: a review of evidence from the genome. Proceedings of the Royal Society B-Biological Sciences 280, 9.

14. Burgarella, C., Lorenzo, Z., Jabbour-Zahab, R., Lumaret, R., Guichoux, E., Petit, R.J., Soto, Á., and Gil, L. (2009). Detection of hybrids in nature: application to oaks (Quercus suber and Q. ilex). Heredity 102, 442-452.

15. Cahill, J.A., Stirling, I., Kistler, L., Salamzade, R., Ersmark, E., Fulton, T.L., Stiller, M., Green, R.E., and Shapiro, B. (2015). Genomic evidence of geographically widespread effect of gene flow from polar bears into brown bears. Molecular ecology 24, 1205-1217.

16. Caro, T. (2005). The Adaptive Significance of Coloration in Mammals. BioScience 55, 125-136.

17. Centeno-Cuadros, A., Razgour, O., García-Mudarra, J.L., Mingo-Casas, P., Sandonís, V., Redondo, A., Ibáñez, C., de Paz, O., Martinez-Alós, S., Pérez Suarez, G., et al. (2019). Comparative phylogeography and asymmetric hybridization between cryptic bat species. Journal of Zoological Systematics and Evolutionary Research 57, 1004-1018.

18. Chaverri, G., Ancillotto, L., and Russo, D. (2018). Social communication in bats. Biological Reviews 93, 1938-1954.

19. Dasmahapatra, K.K., Walters, J.R., Briscoe, A.D., Davey, J.W., Whibley, A., Nadeau, N.J., Zimin, A.V., Hughes, D.S.T., Ferguson, L.C., Martin, S.H., et al. (2012). Butterfly genome reveals promiscuous exchange of mimicry adaptations among species. Nature 487, 94-98.

20. de Lafontaine, G., Prunier, J., Gerardi, S., and Bousquet, J. (2015). Tracking the progression of speciation: variable patterns of introgression across the genome provide insights on the species delimitation between progenitor-derivative spruces (Picea mariana x P-rubens). Molecular ecology 24, 5229-5247.

21. Dinger G. (1991). Winternachweise von Breitflügelfledermaus (Eptesicus serotinus) in Kirchen. Nyctalus (N.F.). 7:614-616.

22. Dietz C, Von Helversen O, Nill D (2009) Bats of Britain, Europe and Northwest Africa. A\&C Black Publishers Ltd. 320-333.

23. Djogbénou, L., Chandre, F., Berthomieu, A., Dabiré, R., Koffi, A., Alout, H., and Weill, M. (2008). Evidence of introgression of the ace-1(R) mutation and of the ace-1 duplication in West African Anopheles gambiae s. s. PloS one 3, e2172.

24. Dunn, B., Paulish, T., Stanbery, A., Piotrowski, J., Koniges, G., Kroll, E., Louis, E.J., Liti, G., Sherlock, G., and Rosenzweig, F. (2013). Recurrent Rearrangement during Adaptive Evolution in an Interspecific Yeast Hybrid Suggests a Model for Rapid Introgression. Plos Genetics 9, 16.

25. Enciso-Romero, J., Pardo-Diaz, C., Martin, S.H., Arias, C.F., Linares, M., McMillan, W.O., Jiggins, C.D., and Salazar, C. (2017). Evolution of novel mimicry rings facilitated by adaptive introgression in 
tropical butterflies. Molecular ecology 26, 5160-5172.

26. Gagnaire, P.A., Albert, V., Jonsson, B., and Bernatchez, L. (2009). Natural selection influences AFLP intraspecific genetic variability and introgression patterns in Atlantic eels. Molecular ecology 18 , 1678-1691.

27. Galván, I., Vargas-Mena, J.C., and Rodríguez-Herrera, B. (2020). Tent-roosting may have driven the evolution of yellow skin coloration in Stenodermatinae bats. Journal of Zoological Systematics and Evolutionary Research 58, 519-527.

28. Giska, I., Farelo, L., Pimenta, J., Seixas, F.A., Ferreira, M.S., Marques, J.P., Miranda, I., Letty, J., Jenny, H., Hackländer, K., et al. (2019). Introgression drives repeated evolution of winter coat color polymorphism in hares. Proceedings of the National Academy of Sciences of the United States of America 116, 24150-24156.

29. Gramlich, S., Wagner, N.D., and Horandl, E. (2018). RAD-seq reveals genetic structure of the F-2generation of natural willow hybrids (Salix L.) and a great potential for interspecific introgression. Bmc Plant Biology 18, 12.

30. Grant, P.R., and Grant, B.R. (1994). Phenotypic and genetics effects of hybridization in Darwin's Finches. Evolution; international journal of organic evolution 48, 297-316.

31. Grant, P.R., and Grant, B.R. (2006). Evolution of Character Displacement in Darwin's Finches. Science (New York, NY) 313, 224-226.

32. Grant, P.R., and Grant, B.R. (2016). Introgressive hybridization and natural selection in Darwin's finches. Biological Journal of the Linnean Society 117, 812-822.

33. Ibáñez, C., García-Mudarra, J.L., Ruedi, M., Stadelmann, B., and Juste, J. (2006). The Iberian contribution to cryptic diversity in European bats. Acta Chiropterologica 8, 277-297.

34. Illumination, I.C.o. (2004). A colour appearance model for colour management systems: CIECAM02. Technical Report No CIE 159: 2004.

35. Jones, G (1997). 'Acoustic signals and speciation: the roles of natural and sexual selection in the evolution of cryptic species', Advances in the Study of Behavior, vol. 26, pp. 317 - 354.

36. Jones, M.R., Mills, L.S., Alves, P.C., Callahan, C.M., Alves, J.M., Lafferty, D.J.R., Jiggins, F.M., Jensen, J.D., Melo-Ferreira, J., and Good, J.M. (2018). Adaptive introgression underlies polymorphic seasonal camouflage in snowshoe hares. Science (New York, NY) 360, 1355-1358.

37. Juste, J., Ibáñez, C., Muñoz, J., Trujillo, D., Benda, P., Karataş, A., and Ruedi, M. (2004). Mitochondrial phylogeography of the long-eared bats (Plecotus) in the Mediterranean Palaearctic and Atlantic Islands. Molecular phylogenetics and evolution 31, 1114-1126.

38. Kalcounis, M.C., and Brigham, R.M. (1995). Intraspecific variation in wing loading affects habitat use by little brown bats (Myotis lucifugus). Canadian Journal of Zoology 73, 89-95.

39. Karatzoglou A, Smola A, Hornik K, Zeileis A (2004). "kernlab - An S4 Package for Kernel Methods in R." Journal of Statistical Software, 11(9), 1-20. http://www.jstatsoft.org/v11/i09/. 
40. Kooyers, N.J., James, B., and Blackman, B.K. (2017). Competition drives trait evolution and character displacement between Mimulus species along an environmental gradient. Evolution; international journal of organic evolution 71, 1205-1221.

41. Kowalski, K., and Rzebik-Kowalska, B. (1991). Mammals of algeria.

42. Latch, E.K., Harveson, L.A., King, J.S., Hobson, M.D., and Rhodes JR. (2006). Assessing Hybridization in Wildlife Populations Using Molecular Markers: A Case Study in Wild Turkeys. The Journal of Wildlife Management 70, 485-492.

43. Ma, F., Zhao, C., Milne, R., Ji, M., Chen, L., and Liu, J. (2010). Enhanced drought-tolerance in the homoploid hybrid species Pinus densata: implication for its habitat divergence from two progenitors. New Phytologist 185, 204-216.

44. Mallarino, R., Grant, P.R., Grant, B.R., Herrel, A., Kuo, W.P., and Abzhanov, A. (2011). Two developmental modules establish 3D beak-shape variation in Darwin's finches. Proceedings of the National Academy of Sciences of the United States of America 108, 4057-4062.

45. Maroco, J. (2010) Análise estatística com utilização do SPSS. $3^{a}$ edição. Edições Silabo.

46. Marsteller, S., Adams, D.C., Collyer, M.L., and Condon, M. (2009). Six cryptic species on a single species of host plant: morphometric evidence for possible reproductive character displacement. Ecological Entomology 34, 66-73.

47. Martinoli, A., Mazzamuto, M.V., and Spada, M. (2020). Serotine Eptesicus serotinus (Schreber, 1774). Handbook of the Mammals of Europe, 1-17.

48. Mavárez, J., Salazar, C.A., Bermingham, E., Salcedo, C., Jiggins, C.D., and Linares, M. (2006). Speciation by hybridization in Heliconius butterflies. Nature 441, 868-871.

49. Meier, J.I., Sousa, V.C., Marques, D.A., Selz, O.M., Wagner, C.E., Excoffier, L., and Seehausen, O. (2017). Demographic modelling with whole-genome data reveals parallel origin of similar Pundamilia cichlid species after hybridization. Molecular ecology 26, 123-141.

50. Melo-Ferreira, J., Seixas, F.A., Cheng, E., Mills, L.S., and Alves, P.C. (2014). The hidden history of the snowshoe hare, Lepus americanus: extensive mitochondrial DNA introgression inferred from multilocus genetic variation. Molecular ecology 23, 4617-4630.

51. Melville, J. (2002). Competition and character displacement in two species of scincid lizards. Ecology letters 5, 386-393.

52. Meyer D, Dimitriadou E, Hornik K, Weingessel A, Leisch F (2012). e1071: Misc Functions of the Department of Statistics, Probability Theory Group (Formerly: E1071), TU Wien. https://cran.rproject.org/web/packages/e1071/index.html.

53. Mims, M.C., Hulsey, C.D., Fitzpatrick, B.M., and Streelman, J.T. (2010). Geography disentangles introgression from ancestral polymorphism in Lake Malawi cichlids. Molecular ecology 19, 940-951.

54. Mingo-Casas P, Sandonı́s V, Obo'n E, Berciano JM, Vazquez-Moron S, Juste J, et al. (2018) First cases of European bat lyssavirus type 1 in Iberian serotine bats: Implications for the molecular epidemiology of bat rabies in Europe. PLoS Negl Trop Dis 12(4): e0006290. 
55. Mondal, M., Casals, F., Xu, T., Dall'Olio, G.M., Pybus, M., Netea, M.G., Comas, D., Laayouni, H., Li, Q., Majumder, P.P., et al. (2016). Genomic analysis of Andamanese provides insights into ancient human migration into Asia and adaptation. Nature Genetics 48, 1066-1070.

56. Muijres F.T., Johansson L.C., Winter Y. and Anders H. (2011). Comparative aerodynamic performance of flapping flight in two bat species using time-resolved wake visualization. J. R. Soc. Interface. 81418-1428.

57. Müller, B., and Peichl, L. (2005). Retinal Cone Photoreceptors in Microchiropteran Bats. Investigative Ophthalmology \& Visual Science 46, 2259-2259.

58. Naisbit, R.E., Jiggins, C.D., and Mallet, J. (2003). Mimicry: developmental genes that contribute to speciation. Evolution \& Development 5, 269-280.

59. Neubaum, M.A., Douglas, M.R., Douglas, M.E., and O'Shea, T.J. (2007). Molecular Ecology of the Big Brown Bat (Eptesicus fuscus): Genetic and Natural History Variation in a Hybrid Zone. Journal of Mammalogy 88, 1230-1238.

60. Nicholls, B., and Racey, P. (2006). Habitat selection as a mechanism of resource partitioning in two cryptic bat species Pipistrellus pipistrellus and Pipistrellus pygmaeus. Ecography 29, 697-708.

61. Nichols, P., Genner, M.J., van Oosterhout, C., Smith, A., Parsons, P., Sungani, H., Swanstrom, J., and Joyce, D.A. (2015). Secondary contact seeds phenotypic novelty in cichlid fishes. Proceedings of the Royal Society B-Biological Sciences 282, 8.

62. Novella-Fernandez, R., Ibañez, C., Juste, J., Clare, E. L., Doncaster, C. P., \& Razgour, O. (2020). Trophic resource partitioning drives fine-scale coexistence in cryptic bat species. Ecology and evolution, 10(24), 14122-14136.

63. Novella-Fernandez, R., Juste, J., Ibáñez, C., Rebelo, H., Russo, D., Alberdi, A., Kiefer, A., Graham, L., Paul, H., Doncaster, C. P., \& Razgour, O. (2021). Broad-scale patterns of geographic avoidance between species emerge in the absence of fine-scale mechanisms of coexistence. Diversity and Distributions, 27, 1606-1618.

64. Ochoa-López, S., Damián, X., Rebollo, R., Fornoni, J., Domínguez, C.A., and Boege, K. (2020). Ontogenetic changes in the targets of natural selection in three plant defenses. New Phytologist 226, 1480-1491.

65. Oliveira, R., Godinho, R., Randi, E., and Alves, P.C. (2008). Hybridization versus conservation: are domestic cats threatening the genetic integrity of wildcats (Felis silvestris silvestris) in Iberian Peninsula? Philosophical transactions of the Royal Society of London Series B, Biological sciences 363, 2953-2961.

66. Ottenburghs, J., Megens, H.J., Kraus, R.H.S., van Hooft, P., van Wieren, S.E., Crooijmans, R., Ydenberg, R.C., Groenen, M.A.M., and Prins, H.H.T. (2017). A history of hybrids? Genomic patterns of introgression in the True Geese. Bmc Evolutionary Biology 17, 14.

67. Pauquet, G., Salzburger, W., and Egger, B. (2018). The puzzling phylogeography of the haplochromine cichlid fish Astatotilapia burtoni. Ecology and Evolution 8, 5637-5648. 
68. Pfennig, D.W., and Murphy, P.J. (2000). Character Displacement in Polyphenic Tadpoles. Evolution; international journal of organic evolution 54, 1738-1749.

69. Pfennig, David W., and Pfennig, Karin S. (2010). Character Displacement and the Origins of Diversity. The American Naturalist 176, S26-S44.

70. Pfennig, K.S. (2007). Facultative Mate Choice Drives Adaptive Hybridization. Science (New York, NY) 318, 965-967.

71. Redgwell, R.D., Szewczak, J.M., Jones, G., and Parsons, S. (2009). Classification of Echolocation Calls from 14 Species of Bat by Support Vector Machines and Ensembles of Neural Networks. Algorithms 2, 907-924.

72. Renaut, S., Grassa, C.J., Yeaman, S., Moyers, B.T., Lai, Z., Kane, N.C., Bowers, J.E., Burke, J.M., and Rieseberg, L.H. (2013). Genomic islands of divergence are not affected by geography of speciation in sunflowers. Nature Communications 4, 8.

73. Sáez, J.A., Galar, M., and Krawczyk, B. (2019). Addressing the Overlapping Data Problem in Classification Using the One-vs-One Decomposition Strategy. IEEE Access 7, 83396-83411.

74. Salazar, C., Baxter, S.W., Pardo-Diaz, C., Wu, G., Surridge, A., Linares, M., Bermingham, E., and Jiggins, C.D. (2010). Genetic Evidence for Hybrid Trait Speciation in Heliconius Butterflies. PLOS Genetics 6, e1000930.

75. Santos, H., Juste, J., Ibáñez, C., Palmeirim, J.M., Godinho, R., Amorim, F., Alves, P., Costa, H., de Paz, O., Pérez-Suarez, G., Martínez-Alos, S., Jones, G. and Rebelo, H. (2014), Shaping of Bat Cryptic Distribution in Iberia. Biological Journal of the Linnean Society 112, 150-162.

76. Schluter, D. (2000). Ecological Character Displacement in Adaptive Radiation. The American Naturalist 156, S4-S16.

77. Schreber J. (1774). Die Säugthiere in Abbildungen nach der Natur, mit Beschreibungen. Erlangen Expedition des Schreber'schen säugthier- und des Esper'schen Schmetterlingswerkes. Ernst Mayr Library of the MCZ, Harvard University, pp 1774-1855.

78. Slager, D.L., Epperly, K.L., Ha, R.R., Rohwer, S., Wood, C., Van Hemert, C., and Klicka, J. (2020). Cryptic and extensive hybridization between ancient lineages of American crows. Molecular ecology 29, 956-969.

79. Song, Y., Endepols, S., Klemann, N., Richter, D., Matuschka, F.-R., Shih, C.-H., Nachman, Michael W., and Kohn, Michael H. (2011). Adaptive Introgression of Anticoagulant Rodent Poison Resistance by Hybridization between Old World Mice. Current Biology 21, 1296-1301.

80. Santana, S.E., Strait, S., and Dumont, E.R. (2011). The better to eat you with: functional correlates of tooth structure in bats. Functional Ecology 25, 839-847.

81. Staubach, F., Lorenc, A., Messer, P.W., Tang, K., Petrov, D.A., and Tautz, D. (2012). Genome patterns of selection and introgression of haplotypes in natural populations of the house mouse (Mus musculus). PLoS Genet 8, e1002891.

82. Temminck C.J. (1840). Monographies de Mammologie, ou description de quelques genres de Mammifères, dont les espèces ont été observes dans les différens Musées de l'Europe 2(302):26-70. 
83. Tene Fossog, B., Ayala, D., Acevedo, P., Kengne, P., Ngomo Abeso Mebuy, I., Makanga, B., Magnus, J., Awono-Ambene, P., Njiokou, F., Pombi, M., et al. (2015). Habitat segregation and ecological character displacement in cryptic African malaria mosquitoes. Evol Appl 8, 326-345.

84. Vázquez-Moron, S., Juste, J., Ibáñez, C., Berciano, J.M., and Echevarria, J.E. (2011). Phylogeny of European bat Lyssavirus 1 in Eptesicus isabellinus bats, Spain. Emerg Infect Dis 17, 520-523.

85. vonHoldt, B.M., Kays, R., Pollinger, J.P., and Wayne, R.K. (2016). Admixture mapping identifies introgressed genomic regions in North American canids. Molecular ecology 25, 2443-2453.

86. Wang, Z.I., Zhang, D.Y., and Wang, G. (2005). Does spatial structure facilitate coexistence of identical competitors. Ecological Modelling 181, 17-23.

87. Wickham, H., Averick, M., Bryan, J., Chang, W., McGowan, L., François, R., Grolemund,G., Hayes, A., Henry, L., Hester, J., Kuhn, M., Pedersen, T., Miller, E., Bache, S.,Müller, K., Ooms, J., Robinson, D., Seidel, D., Spinu, V., ... Yutani, H. (2019). Welcome to the tidyverse. Journal of Open Source Software, 4(43), 1686, https://doi.org/10.21105/joss.01686.

88. Winter, Y., López, J., and von Helversen, O. (2003). Ultraviolet vision in a bat. Nature 425, 612-614.

89. Worthington-Wilmer, J., \& Barratt, E. (1996). A non-lethal method of tissue sampling for genetic studies of chiropterans. Bat Research News, 37(1), 1-4.

90. Yang, W.Z., While, G.M., Laakkonen, H., Sacchi, R., Zuffi, M.A.L., Scali, S., Salvi, D., and Uller, T. (2018). Genomic evidence for asymmetric introgression by sexual selection in the common wall lizard. Molecular ecology 27, 4213-4224.

91. Zhang, W., Dasmahapatra, K.K., Mallet, J., Moreira, G.R.P., and Kronforst, M.R. (2016). Genome-wide introgression among distantly related Heliconius butterfly species. Genome Biology 17, 15.

92. Zhang, W., Kunte, K., and Kronforst, M.R. (2013). Genome-Wide Characterization of Adaptation and Speciation in Tiger Swallowtail Butterflies Using De Novo Transcriptome Assemblies. Genome Biology and Evolution 5, 1233-1245.

\section{Figures}
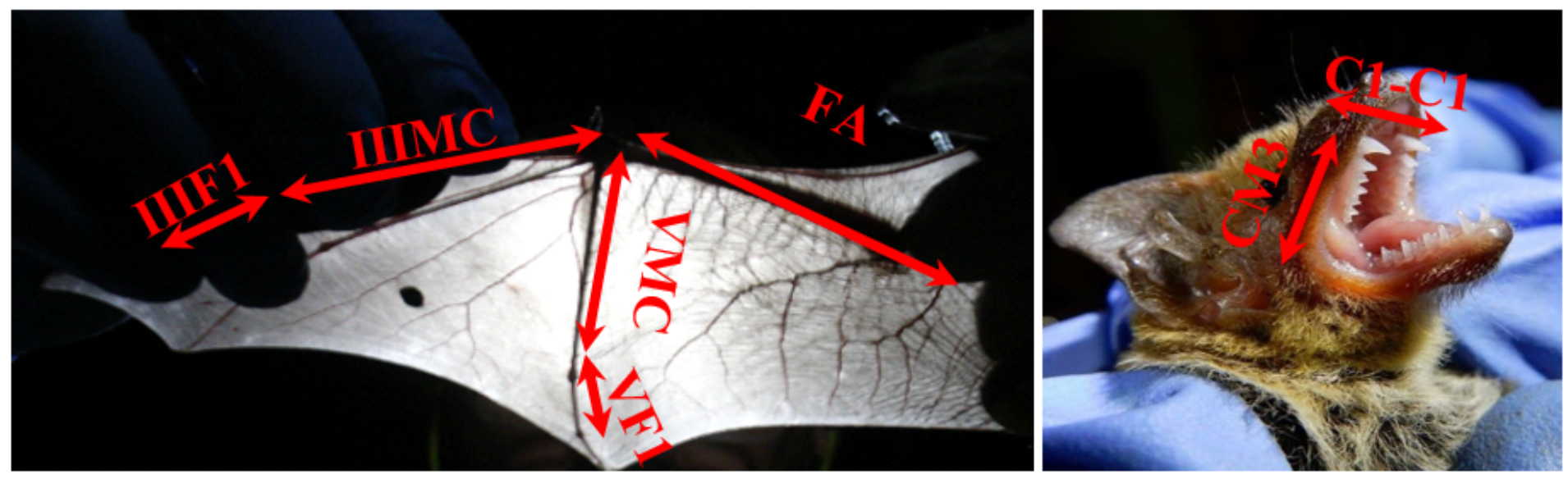
Wing and dentition morphometric measurements taken from Eptesicus bat species during field work.
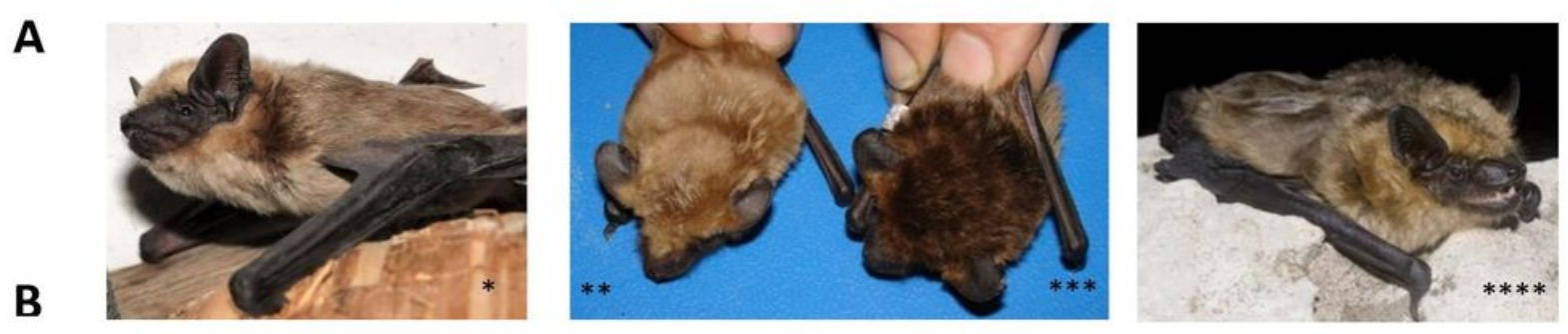

\begin{tabular}{|c|c|c|c|c|c|c|}
\hline & \multicolumn{3}{|c|}{ Dorsal mean colour } & \multicolumn{3}{|c|}{ Ventral mean colour } \\
\hline & $L^{*}$ & $a^{*}$ & $b^{*}$ & $L^{*}$ & $a^{*}$ & $b^{*}$ \\
\hline E. isabellinus allopatric & 40.4 & 5.4 & 15.2 & 51.3 & 5.2 & 17.8 \\
\hline ( $n=6$ individuals) * & \pm 2.18 & \pm 0.61 & \pm 1.29 & \pm 2.74 & \pm 0.94 & \pm 1.70 \\
\hline E. isabellinus sympatric & 38.4 & 6.1 & 17.1 & 52.0 & 5.3 & 18.2 \\
\hline ( $n=39$ individuals) $* *$ & \pm 3.77 & \pm 1.16 & \pm 4.81 & \pm 4.73 & \pm 0.97 & \pm 2.43 \\
\hline Hybrids & 37.4 & 6.8 & 19.1 & 51.9 & 5.5 & 19.4 \\
\hline ( $n=7$ individuals) & \pm 7.06 & \pm 1.66 & \pm 5.74 & \pm 4.20 & \pm 0.78 & \pm 2.42 \\
\hline E. serotinus sympatric & 32.9 & 7.3 & 21.1 & 48.3 & 5.6 & 19.2 \\
\hline ( $\mathrm{n}=17$ individuals) $* * *$ & \pm 6.74 & \pm 2.13 & \pm 8.50 & \pm 5.03 & \pm 0.84 & \pm 3.67 \\
\hline E. serotinus allopatric & 33.6 & 3.8 & 10.9 & 50.3 & 3.4 & 13.9 \\
\hline ( $n=11$ individuals) $* * * *$ & \pm 5.14 & \pm 0.50 & \pm 2.35 & \pm 6.97 & \pm 0.40 & \pm 1.72 \\
\hline$X^{2}{ }_{K S}(4)$ & 17.309 & 32.975 & 28.697 & 6.986 & 26.736 & 23.125 \\
\hline$p$-value & 0.002 & $<0.001$ & $<0.001$ & ns & $<0.001$ & $<0.001$ \\
\hline
\end{tabular}
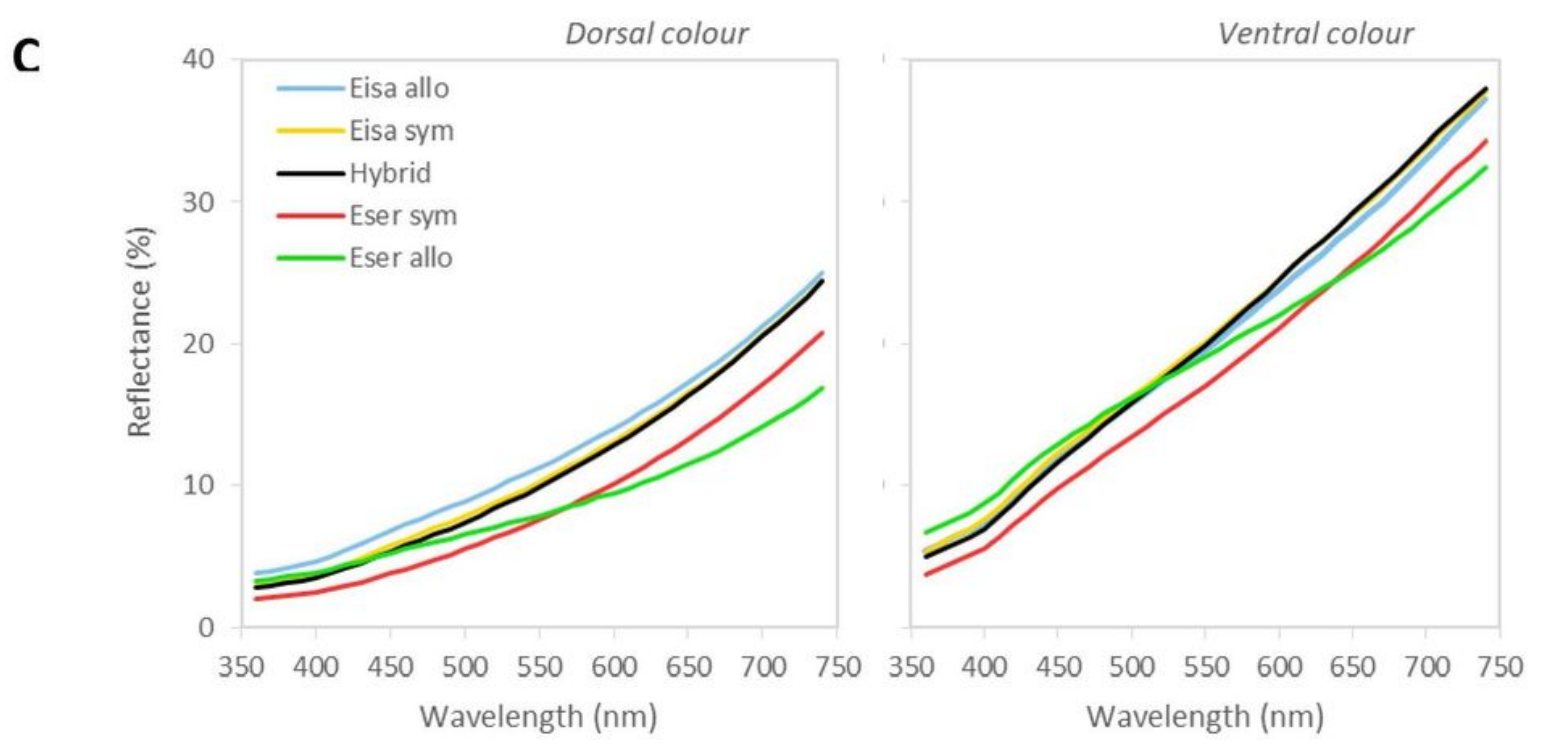

\section{Figure 2}

Colour differences between bat groups. (A) Photographic representation of hair colour of representative specimens of both parental species groups (Eptesicus isabellinus and E. serotinus) as a function of their geographical relationships. (B) Descriptive statistics of dorsal and ventral colour of E. serotinus, $E$. 
isabellinus and their hybrids. Background colour represents the mean colour of the dorsum and belly in the CIELAB colour space of each parental species and in function to their different geographical relationships and their hybrids. (C) Percentage of reflectance measured by colorimeter across the visible wavelength scale. Acronyms are available in Table 1. 
A



B

PCA $1(43.92 \%)$

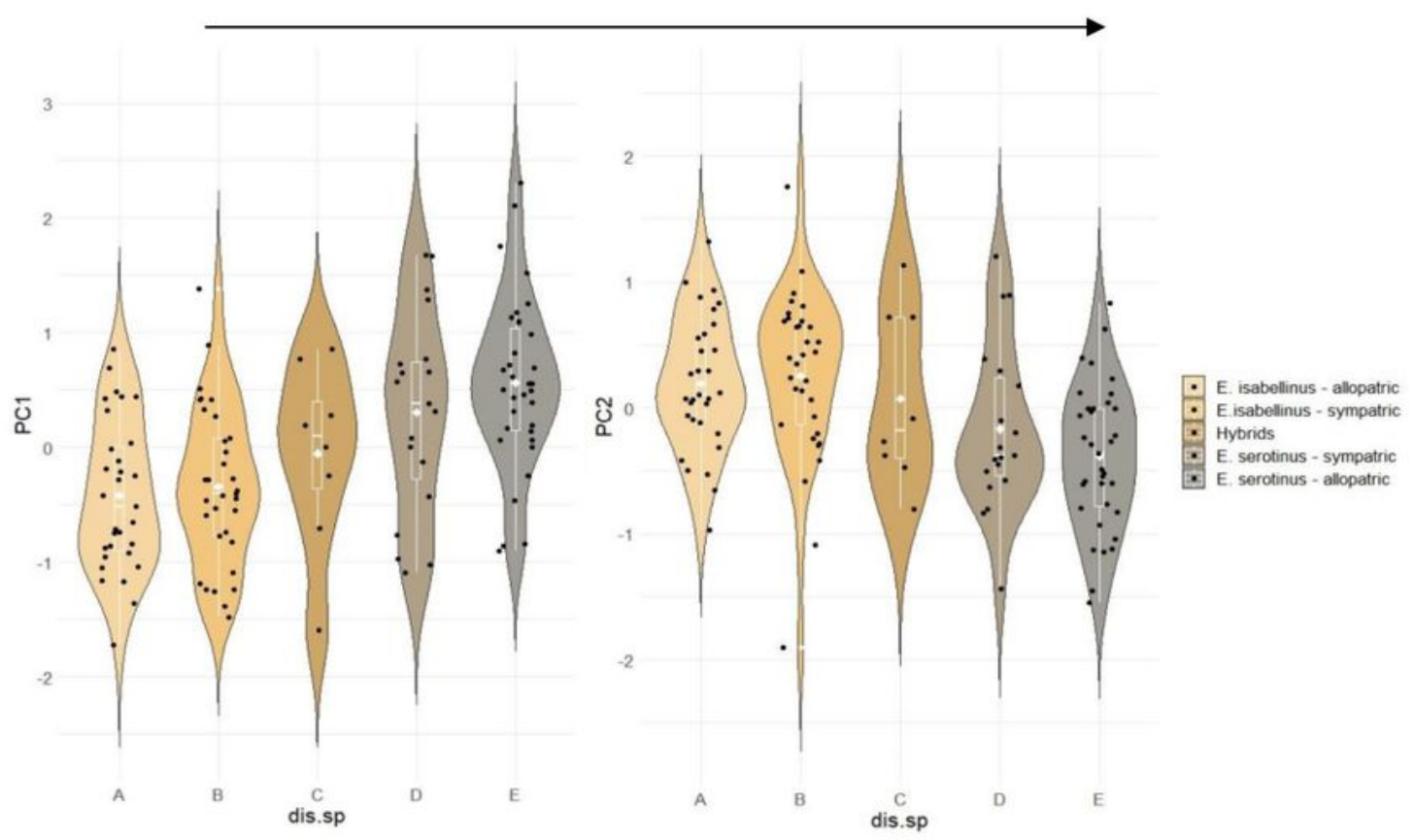

Figure 3

Positioning of each individual in the two-dimensional space defined by the main PCA components retained and their position relative to the original morphometric variables (A). The violin plots represent $E$. isabellinus (allopatric and sympatric), E. serotinus (allopatric and sympatric) and Hybrids PCA scores compared to size (PC1) and shape (PC2) (B). Within violin plots white solid lines boxplots include 
medians (horizontal white line) and averages (white dot); boxes and vertical white lines indicate quartiles and ranges (excluding outliers), respectively. Acronyms are available in Table 1.

A
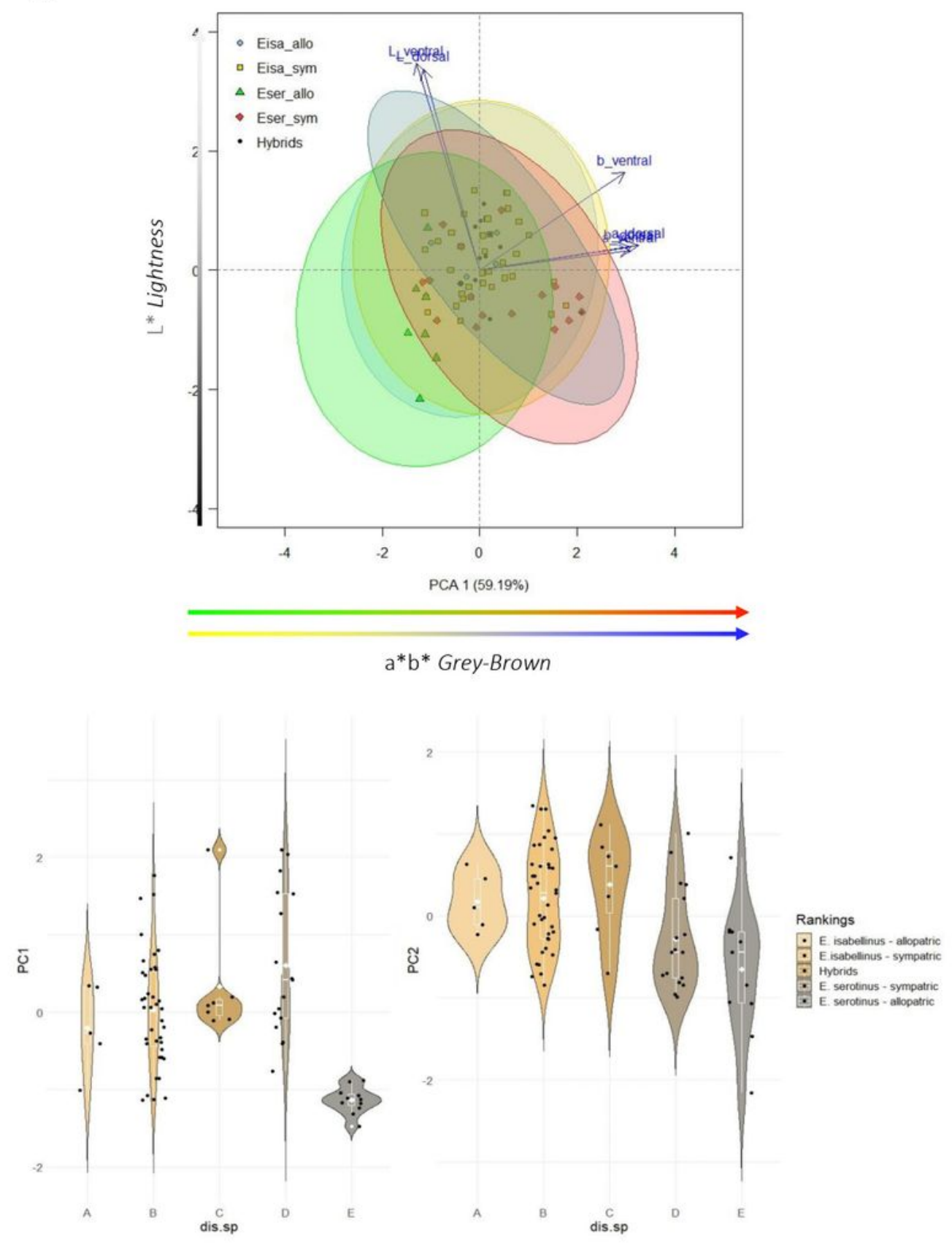

Figure 4 
Positioning of each individual in the two-dimensional space defined by the PCA main components retained and their position relative to the original dorsal colour variables $(\mathbf{A})$. The violin plots represent $E$. isabellinus (allopatric and sympatric), E. serotinus (allopatric and sympatric) and Hybrids PCA scores compared to dorsal $a * b *$ Grey-Brown (PC1 Colour) and dorsal L* lightness (PC2 Colour) (B). Within violin plots white solid lines boxplots include medians (horizontal white line) and averages (white dot); boxes and vertical white lines indicate quartiles and ranges (excluding outliers), respectively. Acronyms are available in Table 1.

\section{Supplementary Files}

This is a list of supplementary files associated with this preprint. Click to download.

- ScientReportsHortaPSupMat2021.docx 